\title{
Study on Neutralization Progress Model of Concrete with Coating Finishing Materials in Outdoor Exposure Conditions Based on the Diffusion Reaction of Calcium Hydroxide
}

\author{
Jae-Hong Park ${ }^{1), *}$, Takuya Hasegawa ${ }^{1)}$, Osamu Senbu' ${ }^{1)}$, and Dong-Cheon Park ${ }^{2)}$ \\ (Received April 20, 2012, Revised June 20, 2012, Accepted June 21, 2012, Published online September 18, 2012)
}

\begin{abstract}
In order to predict the neutralization of concrete which is the reaction of carbonation dioxide from the outside and cement hydration product, such as calcium hydroxide and $\mathrm{C}-\mathrm{S}-\mathrm{H}$, it was studied the numerical analysis method considering change of the pore structure and relative humidity during the neutralization reaction. Diffusion-reaction neutralization model was developed to predict the neutralization depth of concrete with coating finishing material. In order to build numerical analysis models considering outdoor environment and finishing materials, the adaption of proposed model was shown the results of existing outdoor exposure test results and accelerated carbonation test.
\end{abstract}

Keywords: neutralization of prediction, diffusion of calcium hydroxide, rate coefficient of reaction, residual calcium hydroxide, outdoor exposure.

\section{Introduction}

In reinforced concrete structures, usually paint, finishing material, tile, mortar and other finishing material are used for the building's appearance and style as well as for the protection of the building's body. A proper evaluation of the finishing material would enable efficient maintenance in the reinforced concrete structure. Prediction of carbonation is believed to be important for maintenance of reinforced concrete material.

In general, depth of carbonation is in proportion to the square-root of age and it is used for prediction in the squareroot law (Durability of reinforced concrete, Kajima Technical Research Institute Version Section 1963; Toshio 1991) Even though the method with prediction of carbonation process in finishing material based on the square-root law is recommended (Baba and Senbu 1988), but application of the prediction based on the square-root law in two dimensional analysis into three dimensional objects is limited. For this reason, a numerical analysis model based on a theory is required. At the moment, there are a number of suggestions with numerical analysis models of concrete carbonation

\footnotetext{
${ }^{1)}$ Faculty and Graduate School of Engineering, Hokkaido University, Sapporo 060-8628, Japan.

*Corresponding Author; E-mail: p138ak@gmail.com

${ }^{2)}$ Department of Architecture and Ocean Space, Korea

Maritime University, Pusan 606-791, Korea.

Copyright ( The Author(s) 2012. This article is published with open access at Springerlink.com
}

process covered by finishing materials (Fukushima 1991; Kanematsu et al. 2005; Lee and Masuda 2010). But the fact is that adequacy and practicality of carbonation process in an actual environmental condition in relation to the above analysis result have not been sufficiently discussed to come up with a conclusion and actual results. The purpose of this research is to develop a practical and reliable analytical model that predicts carbonation of surface paint, as a part of finishing material, is applied on concrete surface under the actual environment. The reason for not being able to develop a practical and reliable analytical model for the prediction of carbonation under the actual environment was the lack of a perfect explanation of complicated carbonation process (Li and Ishida 2006). Moreover, the same is believed to be necessary to reflect an accurate analytical model showing carbonation process and following change in porosity development. Therefore, in this research, as the first step of practical analytical model development, the carbonation process model was reviewed focusing first on the reaction due to carbon dioxide increase and calcium hydroxide reverse diffusion in consideration to the carbonation main reaction and change in porosity development. Based on the review of the model as well as accelerated carbonation experiment results with finishing material, the sensitivity analysis was performed, the increase factor of carbon dioxide of each finishing material was measured and other necessary information were gathered. Based on these factors along with the accelerated carbonation experiment results and a ten-year outdoor exposure test result on the same material, this research draws the result of performed verification of applicability of the analytical model in relation to the outdoor exposure condition. 


\section{Summary of Analysis}

\subsection{Summary of Accelerated Carbonation Experiment as Analytical Object}

In the accelerated carbonation experiment as an analytical object, Table 1 shows mix proportion of concrete and Table 2 shows type and amount of finishing material applied. Specimen is $100 \times 100 \times 400 \mathrm{~mm}$, and surface paint was applied on four faces of $100 \times 400 \mathrm{~mm}$ and $100 \times 100 \mathrm{~mm}$ sectional surfaces which were sealed with epoxy resin. Five types of new and repair specification were used, and five types of Multiple-layered finishing material E were selected as repair specification. Concrete was casted as standard curing for 28 days, and surface paint was applied by specialty professional after the concrete application has dried up. The condition of accelerated carbonation experiment temperature was at $20{ }^{\circ} \mathrm{C}$, humidity at $65 \% \mathrm{RH}$ and $\mathrm{CO}_{2}$ ratio at $5 \%$. Also, the same specimens used in this accelerated carbonation experiment were used for outdoor exposure test for 10 years in Ishikari, Tsukuba, Tokyo and Okinoerabu. The results from this outdoor exposure tests were used to verify the carbonation process under actual outside condition. Outdoor exposure location's annual average temperature, precipitation, relative humidity is shown in Table 3. The verification of carbonation process was preceded under those conditions.

The verification of carbonation process was preceded under those conditions. The flow chart of the analysis are shown in Fig. 1.

\subsection{Pre-conditions and Basic Equation for} Concrete Carbonation Process of Finishing Material

This research is intended to analyze a phenomenon of concrete carbonation when carbon dioxide in the air penetrates finishing material, reacts with calcium hydroxide and $\mathrm{C}-\mathrm{S}-\mathrm{H}$ and instantly creates calcium carbonate. The below listed are preconditions to the analysis (Hwang et al. 2001; Yoshihiro and Tanano 1991).

(1) In concrete applied finishing material, carbon dioxide penetrates through coating film;

(2) Concrete is a semi-permanent solid material and when carbon dioxide penetrates and spreads, it is assumed to be towards one direction;

(3) Movement of carbon dioxide inside the concrete is distributed in accordance with Fick's First Law;

(4) Reaction of calcium hydroxide and carbon dioxide in concrete is defined as First Reaction;

(5) Concrete becomes denser by carbonation, and the diffusion coefficient is decreased;

(6) Basic equation was developed based on half of the carbon dioxide that penetrated into concrete and the reaction of calcium hydroxide from the previous research (Hwang et al. 2001; Yoshihiro and Tanano 1991).

Also, the porosity decrease rate along with reaction of $\mathrm{C}$ $\mathrm{S}-\mathrm{H}$ and carbon dioxide by calcium carbonate created by the reaction is considered. Eq. (1) is movement of carbon dioxide through coating film of finishing material and spread, Eq. (2) is spread and waste of carbon dioxide in concrete, Eq. (3) is reverse diffusion and waste of calcium hydroxide, Eq. (4) is creation of calcium carbonate.

$$
\begin{aligned}
& \frac{\partial \mathrm{C}_{\mathrm{CO}_{2}}}{\partial t}=\mathrm{D}_{\mathrm{CO}_{2}-\mathrm{Suf}} \frac{\partial^{2} \mathrm{C}_{\mathrm{CO} 2}}{\partial x^{2}} \\
& \frac{\partial \mathrm{C}_{\mathrm{CO}_{2}}}{\partial t}=\mathrm{D}_{\mathrm{CO}_{2}} \frac{\partial^{2} \mathrm{C}_{\mathrm{CO}_{2}}}{\partial x^{2}}-K\left[\frac{\mathrm{C}_{\mathrm{CO}_{2}}}{2}\right]\left[\mathrm{C}_{\mathrm{Ca}(\mathrm{OH})_{2}}\right] \\
& \frac{\partial \mathrm{C}_{\mathrm{Ca}(\mathrm{OH})_{2}}}{\partial t}=\mathrm{D}_{\mathrm{Ca}(\mathrm{OH})_{2}} \frac{\partial^{2} \mathrm{C}_{\mathrm{Ca}(\mathrm{OH})_{2}}}{\partial x^{2}}-\mathrm{K}\left[\frac{\mathrm{C}_{\mathrm{CO}}}{2}\right]\left[\mathrm{C}_{\mathrm{Ca}(\mathrm{OH})_{2}}\right] \\
& \frac{\partial \mathrm{C}_{\mathrm{CaCO}}}{\partial t}=\mathrm{K}\left[\frac{\mathrm{C}_{\mathrm{CO}}}{2}\right]\left[\mathrm{C}_{\mathrm{Ca}(\mathrm{OH})_{2}}\right]
\end{aligned}
$$

where $t$ is the time, $x$ is the distance from the surface of the concrete, $\mathrm{D}_{\mathrm{CO}_{2}}$ is the diffusion coefficient of the carbon dioxide, $\mathrm{D}_{\mathrm{Ca}(\mathrm{OH})_{2}}$ is the diffusion coefficient of calcium

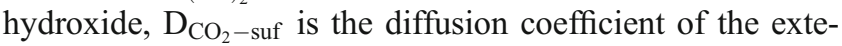
rior material, $\mathrm{C}_{\mathrm{CO}_{2}}$ is the concentration of carbon dioxide, $\mathrm{D}_{\mathrm{Ca}(\mathrm{OH})_{2}}$ is the concentration of calcium hydroxide, $\mathrm{C}_{\mathrm{CaCO}_{3}}$ is the concentration of calcium carbonate, and $\mathrm{R}$ is the rate constant of the reaction.

Initial conditions

$$
\begin{aligned}
& t=0 \\
& x>0: \mathrm{C}_{\mathrm{CO}_{2}}=0, \mathrm{C}_{\mathrm{Ca}(\mathrm{OH})_{2}}=\mathrm{C}_{\mathrm{Ca}(\mathrm{OH})_{2}-\text { Init }}
\end{aligned}
$$

Equations (5-8) are pre-conditions and boundary conditions. Average ratio of $\mathrm{C}_{3} \mathrm{~S}$ and $\mathrm{C}_{2} \mathrm{~S}$ in typical Portland cement are about 50 and $26 \%$, and when typical Portland cement hydration ratio $\alpha$ is 100 , about $30 \%$ of calcium hydroxide quantity is generated. Therefore, the calcium hydroxide mole density in concrete is expressed as unit cement quantity $\mathrm{Q}$ and hydration ratio $\alpha$ in Eq. (6) (Tanano and Masuda 1988).

\begin{tabular}{|c|c|c|c|c|c|c|c|c|}
\hline \multirow[t]{2}{*}{$\mathrm{W} / \mathrm{C}(\%)$} & \multirow[t]{2}{*}{ S/A (\%) } & \multicolumn{4}{|c|}{ Unit amount $\left(\mathrm{kg} / \mathrm{m}^{3}\right)$} & \multirow[t]{2}{*}{ Slump (mm) } & \multirow[t]{2}{*}{ Air content $(\%)$} & \multirow{2}{*}{$\begin{array}{c}\text { Compressive } \\
\text { strength (N/ } \\
\left.\mathrm{mm}^{2}\right)\end{array}$} \\
\hline & & Water & Cement & Fine aggregate & Aggregate & & & \\
\hline 60 & 47.9 & 176 & 271 & 862 & 952 & 180 & 4.5 & 29 \\
\hline
\end{tabular}

$$
\mathrm{Ca}=\frac{0.3 \cdot Q \cdot \alpha}{74}
$$

where $\mathcal{Q}$ is the unit amount unit amount of cement $\left(\mathrm{kg} / \mathrm{m}^{3}\right)$, and $\alpha$ is the hydration rate (\%)

Table 1 Mix proportion of concrete. 
Table 2 Finishing material used and general outline.

\begin{tabular}{|c|c|c|c|c|c|c|c|}
\hline \multirow[t]{2}{*}{ Num } & \multirow[t]{2}{*}{ Type } & \multirow{2}{*}{$\begin{array}{c}\text { Finishing } \\
\text { material }\end{array}$} & \multicolumn{3}{|c|}{ Usage $\left(\mathrm{kg} / \mathrm{m}^{2}\right)$} & \multirow[t]{2}{*}{$\mathrm{W} / \mathrm{C}(\%)$} & \multirow{2}{*}{$\begin{array}{l}\text { Thickness } \\
(\mathrm{mm})\end{array}$} \\
\hline & & & Top & Middle & Down & & \\
\hline 1 & \multirow[t]{5}{*}{$\begin{array}{c}\text { Primary } \\
\text { specification }\end{array}$} & $\begin{array}{c}\text { Multiple-layered finishing material } \\
E \text { (TP: solvent type acryl) }\end{array}$ & 0.09 & 1.00 & 0.15 & 60 & 2.11 \\
\hline 2 & & $\begin{array}{c}\text { Multiple-layered finishing material } \\
E \text { (TP: } 2 \text { liquid urethane) }\end{array}$ & 0.14 & 1.00 & 0.10 & 60 & 0.34 \\
\hline 3 & & $\begin{array}{l}\text { Waterproof of multiple-layered } \\
\quad \text { finishing material } E\end{array}$ & 0.15 & 1.00 & - & 60 & 1.53 \\
\hline 4 & & $\begin{array}{c}\text { Waterproof of multiple-layered } \\
\text { finishing material } E \text { (TP: } 2 \text { liquid } \\
\text { elastic urethane) }\end{array}$ & 0.15 & 1.10 & 0.14 & 60 & 1.55 \\
\hline 5 & & Thin coating material $E$ & 0.09 & 1.20 & - & 60 & 0.09 \\
\hline 6 & \multirow[t]{5}{*}{$\begin{array}{c}\text { Repair } \\
\text { specification }\end{array}$} & $\begin{array}{c}\text { Specification } 1+\text { non-cement of } \\
\text { aqueous material base adjustment- } \\
\text { aqueous } 1 \text { liquid urethane }\end{array}$ & 1.50 & - & 0.13 & 60 & 1.31 \\
\hline 7 & & $\begin{array}{c}\text { Specification } 1+\text { non-cement of } \\
\text { aqueous material base adjustment- } \\
\text { aqueous } 1 \text { liquid silicon }\end{array}$ & 1.50 & - & 0.13 & 60 & 2.21 \\
\hline 8 & & $\begin{array}{c}\text { Specification } 1+\text { non-cement of } \\
\text { aqueous material base adjustment- } \\
\text { aqueous } 2 \text { liquid urethane }\end{array}$ & 1.50 & - & 0.10 & 60 & 1.13 \\
\hline 9 & & $\begin{array}{l}\text { Specification } 1+\text { waterproof type } \\
\text { thin coating material } E\end{array}$ & 0.15 & 1.00 & - & 60 & 2.20 \\
\hline 10 & & $\begin{array}{c}\text { Specification } 1+\text { waterproof type of } \\
\text { multiple-layered (TP: aqueous } 2 \\
\text { liquid urethane) }\end{array}$ & 0.15 & 1.10 & 0.14 & 60 & 1.04 \\
\hline
\end{tabular}

Table 3 Outdoor exposure area and general outline.

\begin{tabular}{|c|c|c|c|c|c|c|}
\hline \multirow[t]{2}{*}{ Area } & \multicolumn{3}{|c|}{ Temperature $\left({ }^{\circ} \mathrm{C}\right)$} & \multirow{2}{*}{$\begin{array}{c}\text { Amount of } \\
\text { precipitation }(\mathrm{mm})\end{array}$} & \multirow{2}{*}{$\begin{array}{c}\text { Relative humidity } \\
(\%)\end{array}$} & \multirow{2}{*}{$\begin{array}{c}\begin{array}{l}\text { Distance from coast } \\
(\mathrm{km})\end{array} \\
\end{array}$} \\
\hline & Ave & Max & Min & & & \\
\hline Ishikari & 7.5 & 11.4 & 3.8 & 1037.7 & 70 & 3 \\
\hline Tsukuba & 13.5 & 18.9 & 8.4 & 1235.6 & 63 & 45 \\
\hline Tokyo & 15.9 & 19.7 & 12.5 & 1466.7 & 75 & 7 \\
\hline Okinoerabu & 22.3 & 24.8 & 20.2 & 1983.1 & 74 & 0.5 \\
\hline
\end{tabular}

Boundary condition.

$$
\begin{aligned}
& t>0 \\
& x=0: \mathrm{C}_{\mathrm{CO}(\mathrm{OH})_{2}}=0, \mathrm{C}_{\mathrm{CO}_{2}}=\varepsilon \cdot \mathrm{C}_{\mathrm{CO}_{2}-\mathrm{Out}} \\
& x \rightarrow+\infty: \mathrm{C}_{\mathrm{CO}(\mathrm{OH})_{2}}=\mathrm{C}_{\mathrm{Ca}(\mathrm{OH})_{2}-\text { Init }}, \mathrm{C}_{\mathrm{CO}_{2}}=0
\end{aligned}
$$

Density of carbon dioxide on concrete surface $\mathrm{C}_{\mathrm{C}_{2}}$ is determined in consideration of concrete porosity. For example, when concrete porosity is $20 \%$; $20 \%$ of surrounding carbon dioxide density $\mathrm{C}_{\mathrm{CO}_{2}-\text { Out }}$ is the boundary condition. If the surrounding carbon dioxide density is assumed to be $5 \%$, volume density of carbon dioxide on concrete surface is $1 \%$, and it is $0.4 \mathrm{e}-6\left(\mathrm{~mol} / \mathrm{cm}^{3}\right)$ in mole density. Therefore, outdoor carbon dioxide density $0.05 \%$ is $0.00464 \mathrm{e}-6\left(\mathrm{~mol} / \mathrm{cm}^{3}\right)$.

\subsection{Diffusion Coefficient of Carbon Dioxide and Calcium Hydroxide in Concrete}

Obtaining the diffusion coefficient of carbon dioxide in concrete is a very difficult task in the accelerated carbonation experiment. One of the reasons to this is that the porosity structure is changed by calcium carbonate created by carbonation.

Papadakis et al. (1991) and Wittmann et al. (1994) suggest the diffusion coefficient equation which uses spread disk cell to measure percentage of porosity in concrete and relative 


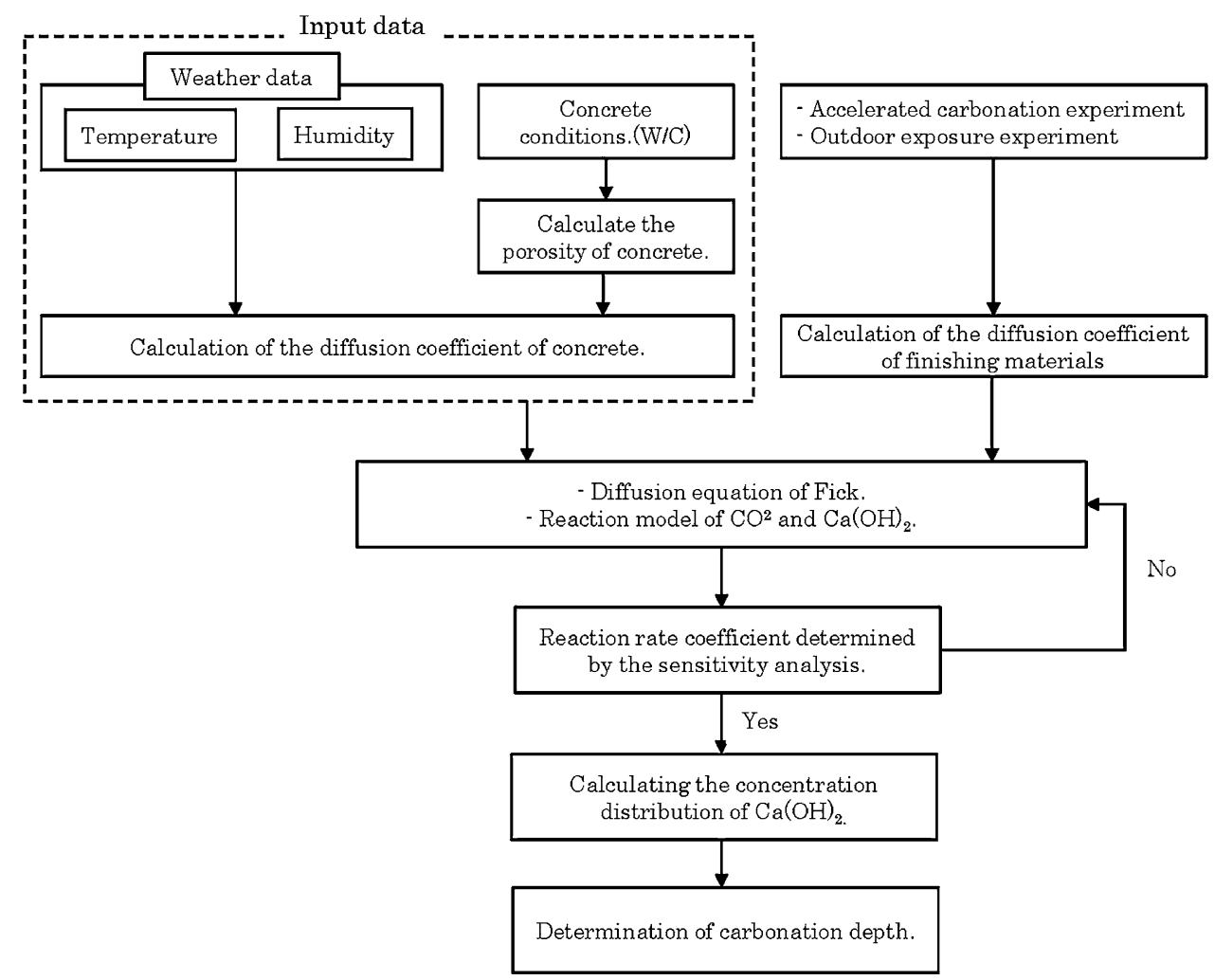

Fig. 1 Flow chart of the analysis.

humidity as a variable, but this analysis is based on Papadakis et al. equation (1991) in Eq. (9).

$$
\mathrm{D}_{\mathrm{C}}=1.64 \times 10^{-6} \varepsilon^{1.8}\left(\frac{1-\mathrm{RH}}{100}\right)^{2.2}
$$

where $\varepsilon$ is the total porosity (\%), and $\mathrm{RH}$ is the relative humidity $(\%)$

$$
\mathrm{D}_{\mathrm{Ca}(\mathrm{OH})_{2}}=\exp (0.0767528 w-25.1797)
$$

where $w$ is the moisture content (\%)

Fukushima (1991) suggests that concrete inside calcium hydroxide reverse diffusion coefficient $\mathrm{D}_{\mathrm{Ca}(\mathrm{OH})_{2}}$ in Eq. (9) may be expressed as an exponential function with moisture content (\%) as a variable. Calcium hydroxide reverse diffusion has been verified in the tests by Chang and Chen (2006), and it is believed that moisture content is the governing factor.

In this research, the approximate range of calcium hydroxide was generated based on Eq. (10), and the test result values were adjusted by the sensitivity analysis.

\subsection{Percentage of Porosity Decrease}

As Eq. (11) shows, the porosity in concrete decreases in the process of carbon dioxide and calcium hydroxide reaction, but changes in porosity volume will affect moisture content which is necessary to be considered. In this research, change in percentage of porosity is taken into account by the development of a regression curve based on previously performed test data.

$$
\varepsilon^{\prime}=\alpha \cdot \varepsilon_{0}
$$

where $\varepsilon^{\prime}$ is the total porosity after carbonation, $\alpha$ is the reduction coefficient of porosity, and $\varepsilon_{0}$ is the total porosity before carbonation. $\alpha$ is given by

$$
\alpha=0.92-3.95 \cdot 0.94^{\mathrm{W} / \mathrm{C}}
$$

where $\mathrm{W} / \mathrm{C}$ is the water/cement ratio (\%)

Relationship of water-cement ratio and percentage of porosity decrease factor is shown on Fig. 2 based on previous test data ( $\mathrm{Li}$ and Ishida 2006; Papadakis et al. 1991; Ngala and Page 1997; Park 2007; Park 2008). They appear

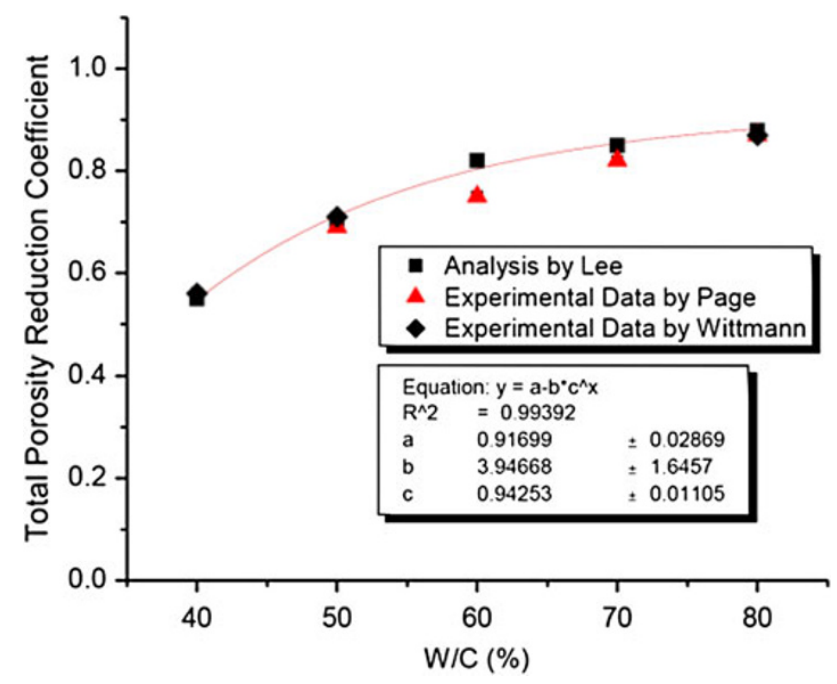

Fig. 2 Change on porosity due to carbonation (7), (13), (15), (18). 
to significantly relate to each other, and Eq. (12) was generated from the relationship.

\subsection{Carbonation Determination Standard}

Because the remaining amount of calcium hydroxide might not be clearly determined in this analysis of accelerated carbonation experiment, half of earlier calcium hydroxide density was assumed to be the area of boundary of carbonation based on previous research (Tanano and Masuda 1988).

\subsection{Prediction of Carbonation Process under Outdoor Exposure Condition}

Because the model explained so far is with the assumption of the carbonation facilitation test $\left(20{ }^{\circ} \mathrm{C}, 60 \% \mathrm{RH}, \mathrm{CO}_{2}\right.$ density $5 \%$ ), prediction of process of outdoor exposure requires consideration of possible environmental conditions.

The possible environmental conditions affecting carbonation are determined to be temperature, humidity and carbon dioxide density. In this research, temperature and humidity are based on annual average data from the nearest local weather center and observatory, and Carbon Dioxide density is assumed to be $0.04 \%$.

\subsection{Influence of Finishing Material into Temperature and Humidity in Concrete}

It is believed that the finishing material applied influence temperature and humidity in concrete. But in relation to the influence of finishing material on temperature and humidity measured for 1 year in Sapporo under outdoor exposure (Japan Society for Finishing Technology 2009), which shows no significant influence in temperature, this research is based on the assumption that temperature doesn't influence finishing material.

And on the subject of humidity, even though Fig. 3 shows a change in values when surface finish material is applied and when not applied, average value measured for 1 year of outdoor exposure, Multiple-layered finishing material $E$ shows $1.29 \%$ and waterproof of multiple-layered finishing material $E$ is $3.16 \%$. Further, as it is expected to be closed to normal condition in a long term, humidity change for 10 years is assumed to be closed to 0 in our analysis.

\section{Analysis Result}

\subsection{Sensitivity Analysis to Obtain Reaction Rate Constant and Calcium Hydroxide Diffusion Coefficient}

In comparison to the research to obtain the carbon dioxide diffusion coefficient, there are not many researches that obtain the reaction rate constant and calcium hydroxide diffusion coefficient. Sensitivity analysis was performed to predict reaction rate constant and calcium hydroxide diffusion coefficient by comparing the result of our research and the results from previously performed test values. In Fig. 4, the test value was from the research conducted by Park (2007) which was used to compare with this analysis value.
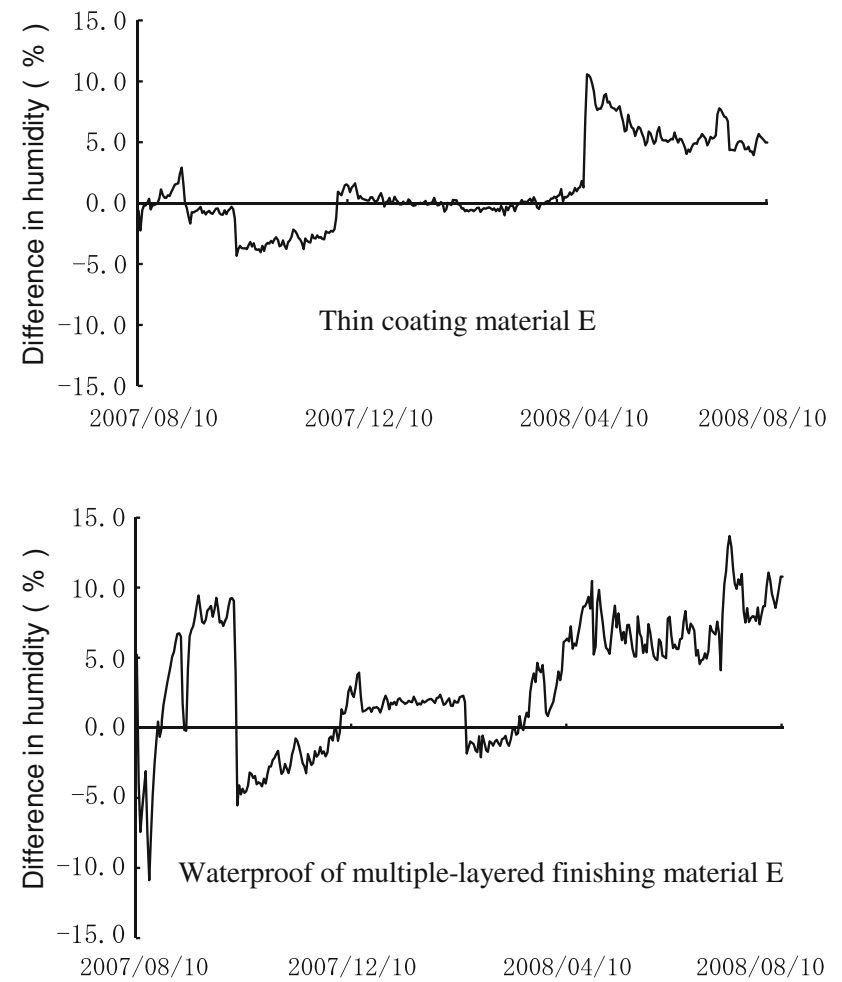

Fig. 3 Changes in relative humidity of inside concrete construction were the coating finishing material in Sapporo City.

W/C ratio is $65 \%$, concrete was casted for $24 \mathrm{~h}$ at $23{ }^{\circ} \mathrm{C}$ after concrete pouring, after the cylinder was removed it was preserved/casted for 28 days at $23{ }^{\circ} \mathrm{C}$ and relative humidity $100 \%$ before accelerated carbonation experiment. The accelerated carbonation experiment device was set under the condition of $23{ }^{\circ} \mathrm{C}$ and relative humidity $70 \%$, carbon dioxide density $20 \%$, after 8 and 16 weeks TGA was utilized to measure the amount of calcium hydroxide and calcium carbonate. Figure 3 shows comparison of measurement result and analysis result at 8 and 16-week. Overall calcium hydroxide diffusion coefficient was $1 \mathrm{e}-11\left(\mathrm{~m}^{2} / \mathrm{s}\right)$, and reaction rate constant was $5 \mathrm{e}-4-5 \mathrm{e}-5\left(\mathrm{~m}^{3} / \mathrm{mol} / \mathrm{s}\right)$ which showed significantly high reproducibility.

\subsection{Obtaining Carbon Dioxide Diffusion Coefficient of Finishing Material}

This analysis is intended to obtain carbon dioxide diffusion coefficient of finishing material by performing sensitivity analysis based on accelerated carbonation experiment result and carbonation model as shown earlier. Each finishing material was applied on concrete and accelerated carbonation experiment which were performed for 24 weeks $\left(20{ }^{\circ} \mathrm{C}, 60 \% \mathrm{RH}, \mathrm{CO}_{2}\right.$ concentration of $\left.5 \%\right)$. The analysis results of calcium hydroxide distributions are shown in Fig. 3. In this analysis, half of the earlier calcium hydroxide density was 655 ; carbonation depth was obtained at that point. From the analysis result, calcium hydroxide density distribution appears to have been significantly influenced by the thickness of finishing material against the penetration of carbon dioxide because the remaining calcium hydroxide 

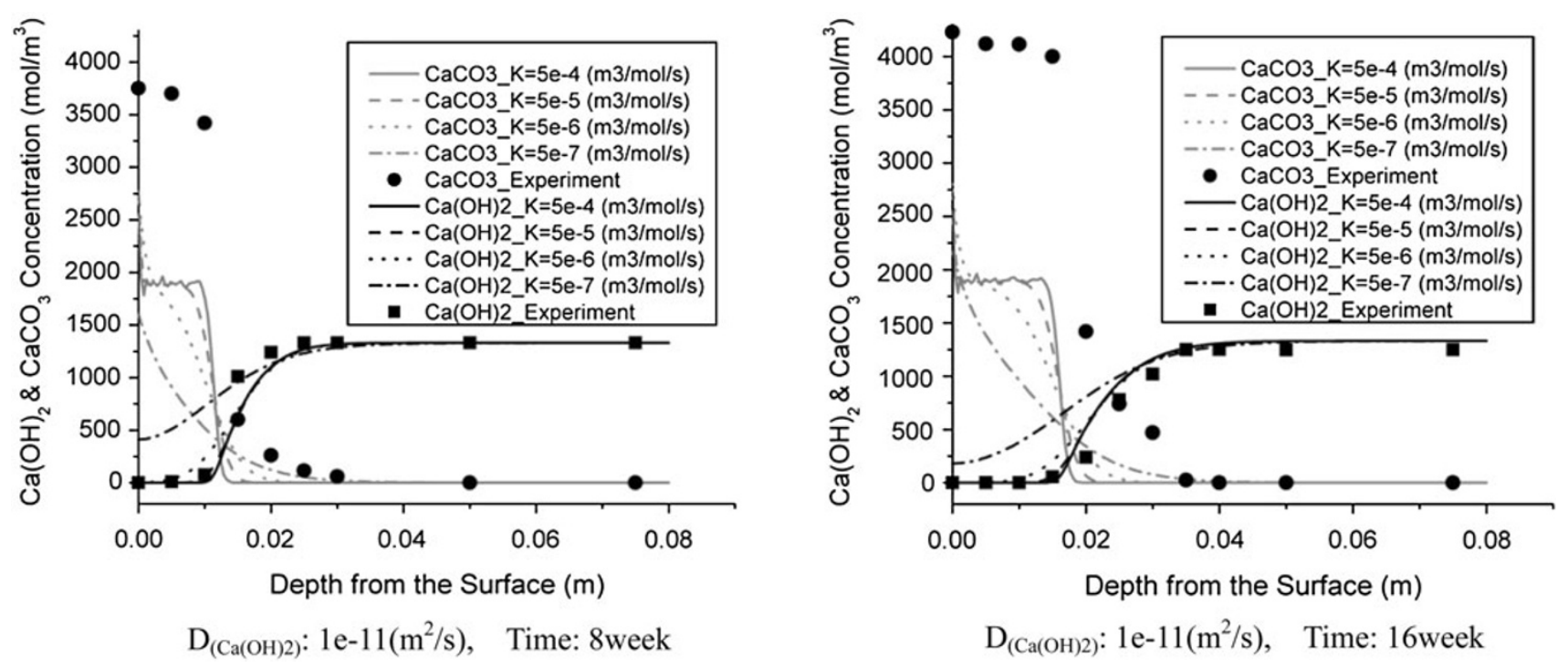

Fig. 4 Concentration distributions of calcium hydroxide and calcium carbonate.

density distribution of thicker repair specification was at a higher level. Figure 5 shows the carbon dioxide diffusion coefficient of each finishing material.

The new specification tends to show higher carbon dioxide diffusion coefficient than repair specification. Figure 6 shows the diffusion coefficient of carbon dioxide of each surface finishing materials. The newer type tends to show higher coefficient of carbon dioxide.

\subsection{Comparison of Outdoor Exposure Test Result and Analysis Result}

Figure 6 shows analysis results of test specimens whereby one finishing material was applied while another finishing material was not applied. Both applications were done in Tokyo. Furthermore, the values of calcium hydroxide diffusion coefficient $1 \times E-11\left(\mathrm{~m}^{2} / \mathrm{s}\right)$ and reaction rate constant $5 \times E-5\left(\mathrm{~m}^{3} / \mathrm{mol} / \mathrm{s}\right)$, obtained from sensitivity analysis, were input because they matched with the test value/data. This figure verifies the match with the outdoor exposure test result. Figure 7 shows calcium hydroxide density change of each finishing material for 10 years of the outdoor exposure test performed in Tokyo under the same condition.

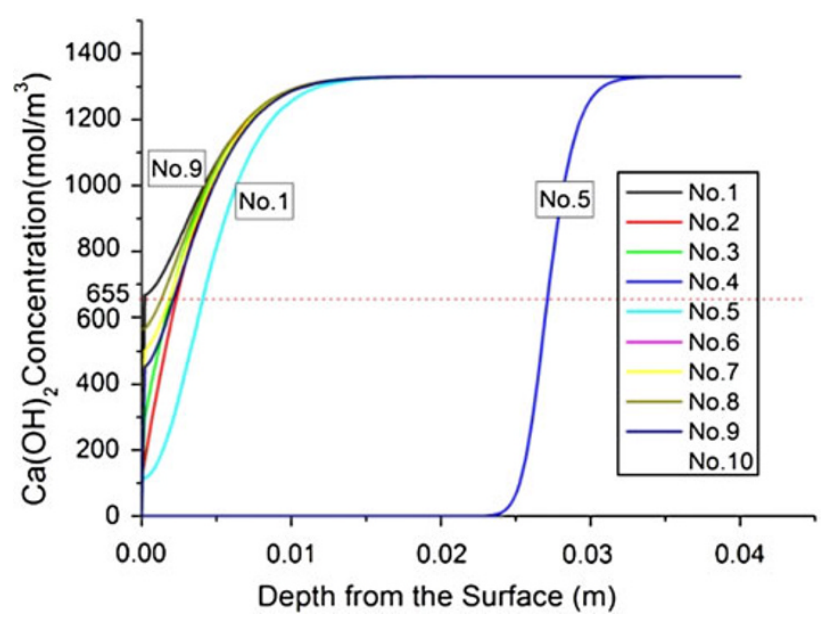

Fig. 5 Concentration distribution of the residual calcium hydroxide after 24 weeks of accelerated.

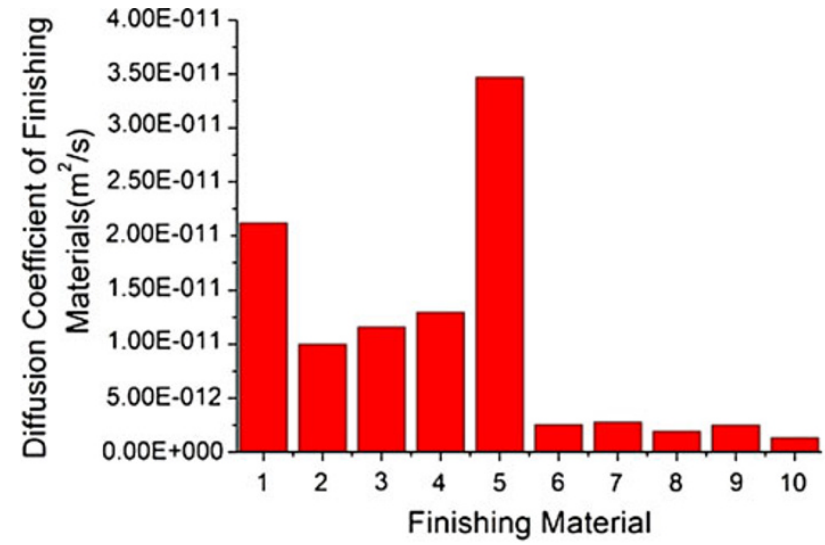

Fig. 6 Diffusion coefficient of carbon dioxide each finishing material.

Calcium hydroxide density change inside of each concrete specimen applied with repair specification tends to be higher than new specification except type 5 wherein carbonation did not occur. For this reason, with the finishing material being utilized in the analysis, there is no change in the carbon dioxide diffusion coefficient and it is believed that carbonation does not occur under the condition of outdoor exposure in Tokyo. Here, Fig. 8 shows suggested Eq. (13) suggested by Baba and Senbu (1988);

$$
C=A\left(\sqrt{t+R^{2}-R}\right)
$$

where $C$ is the carbonation depth (mm), and $A$ is the rate of neutralization coefficient $\left(\mathrm{mm} / \mathrm{day}^{-1 / 2}\right)$, and $t$ is the time (day), and $R$ is the neutralization resistance $\left(\right.$ day $^{-1 / 2}$ ).

Carbonation resistance factor $R$ obtained from carbonation facilitation test result; carbonation speed factor $A$ of specimen wherein no surface finish material was applied and went through outdoor exposure test result carbonation depth measured from factor $A$; and carbonation depth analysis value. In addition, carbonation depth obtained from Eq. (13) indicates predicted value when surface finish material is not exposed heat under outdoor exposure 

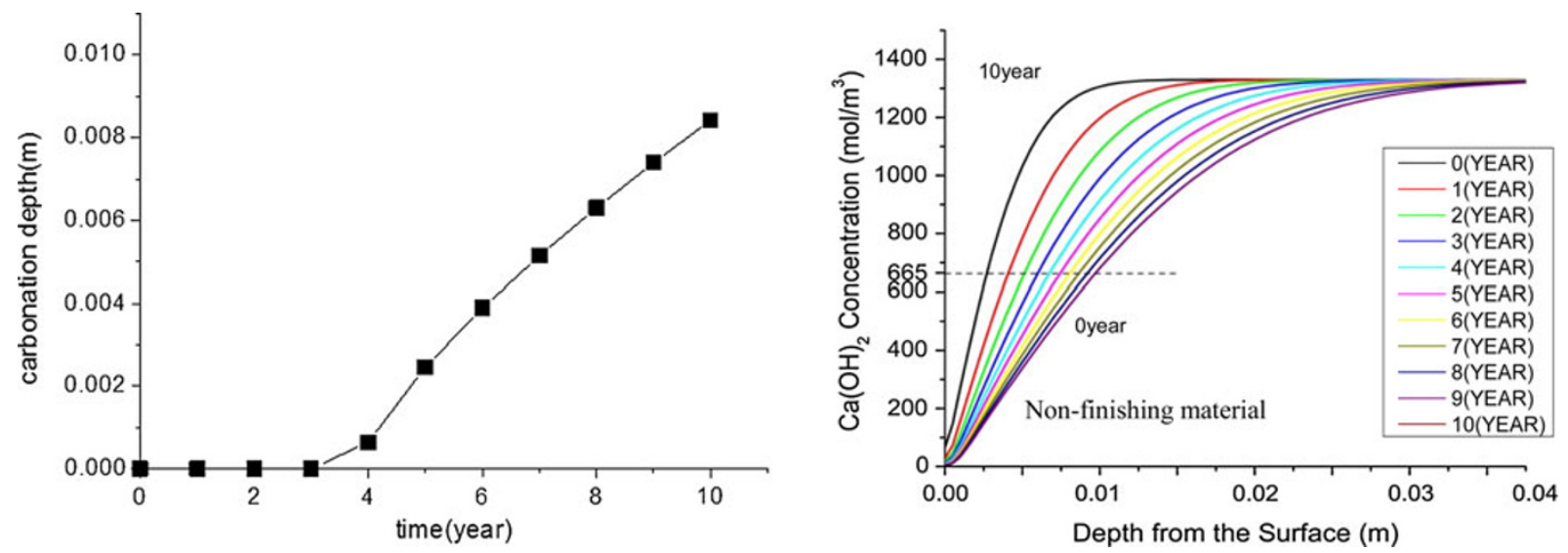

Fig. 7 Analysis of progression of carbonation without finishing material carbonation (Tokyo).
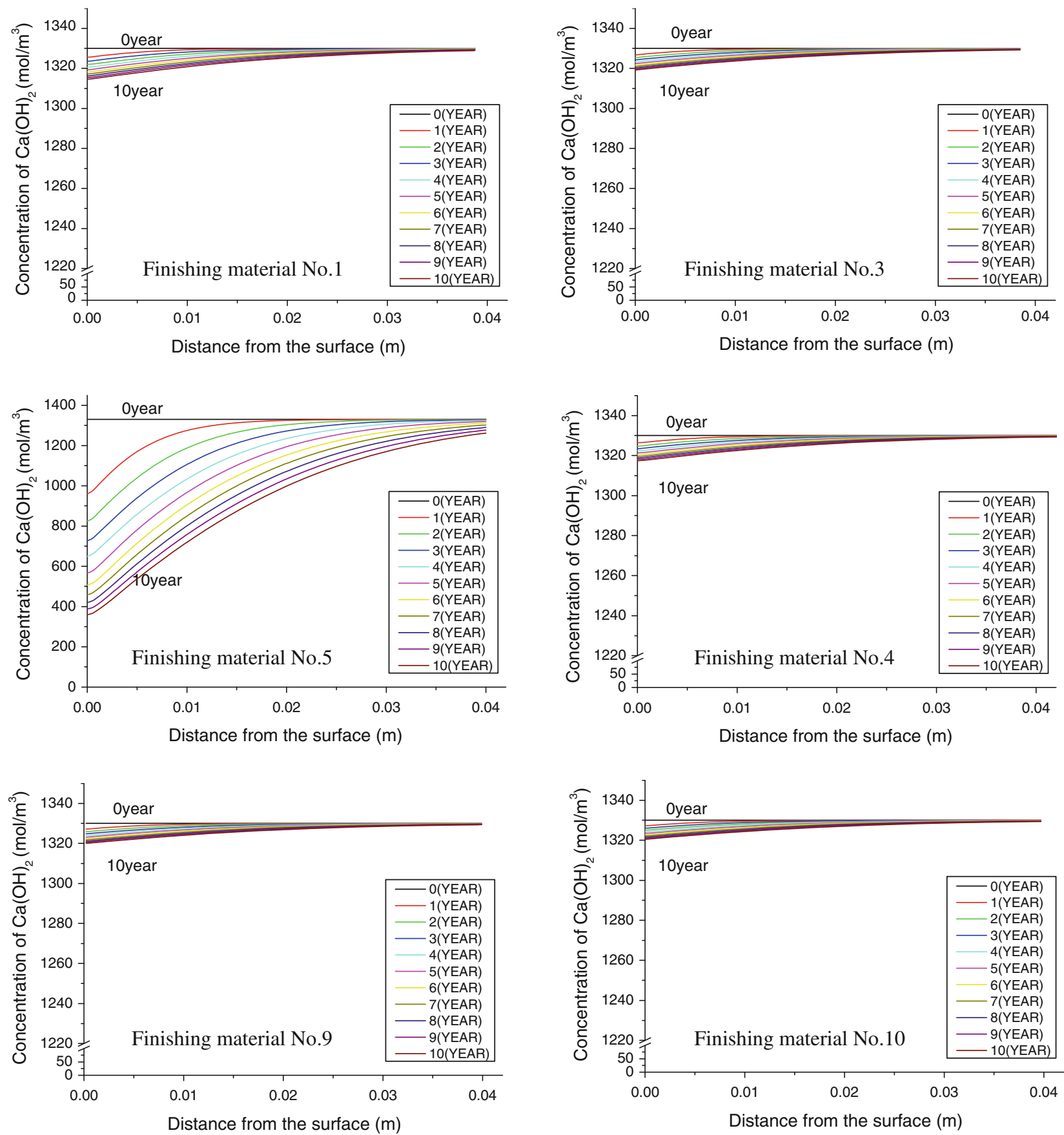

Fig. 8 Changes in the concentration of calcium hydroxide by progressive carbonation of each finishing materials. 


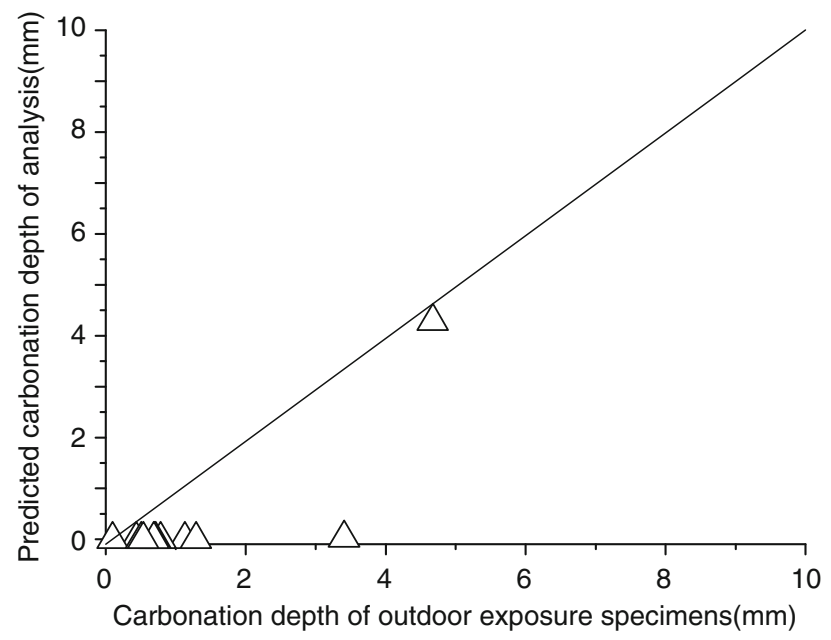

Fig. 9 Carbonation depth of out door exposure test results and the results of this.

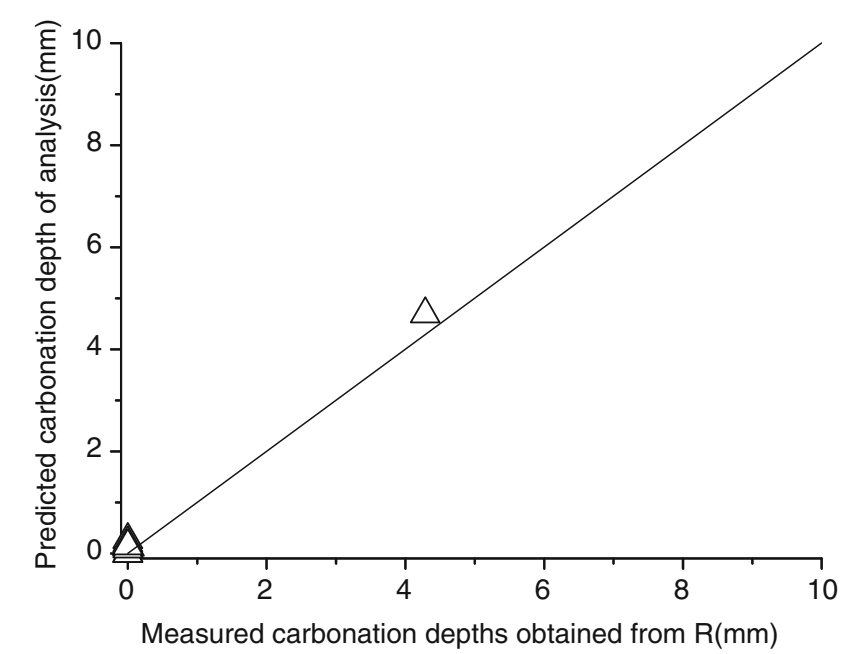

Fig. 10 Carbonation depth of analysis and estimation equation was proposed by Baba (1988).

condition. Because the predicted value under outdoor exposure condition and the analysis value almost match each other, Baba's equation is believed to be reasonably acceptable and our analysis is adequate unless surface finish material is exposed to significantly high heat. Figure 9 shows the carbonation depth measured and carbonation depth from our analysis. From this result of actual outdoor exposure test, the surface finish material which has not carbonated shows as if carbonation has occurred in Fig. 10. It is believed to be due to the heat which was caused by aging. This is believed to be an important issue, this being a possible influence in surface finish material carbonation resistance, and it may be considered in the future analysis. Unfortunately, evaluation of heat on surface finish material is not clear at this stage and future studies on the said subject need to be conducted.

\section{Conclusion}

With an assumption that carbonation is the reaction of carbon dioxide penetrated through finishing material and diffusion, the calcium hydroxide and $\mathrm{C}-\mathrm{S}-\mathrm{H}$, carbonation model was developed while considering the porosity structure after carbonation and was reviewed utilizing previously performed testing data. Our findings are as listed below:

(1) Carbon dioxide diffusion coefficient depends on thickness of the finishing material based on accelerated carbonation experiment result.

(2) Carbonation process in consideration of porosity change in concrete caused by carbonation is suggested.

(3) Prediction of carbonation process under outdoor exposure condition was possible applied by analysis of model developed in this research with accelerated carbonation experiment.

(4) Deterioration of finishing material must be considered to predict carbonation depth under the actual environment.

\section{Open Access}

This article is distributed under the terms of the Creative Commons Attribution License which permits any use, distribution, and reproduction in any medium, provided the original author(s) and the source are credited.

\section{References}

Baba, A., \& Senbu, O. (1988). A theoretical consideration on proceeding of carbonation in concrete after renewal by coating (Vol. 10, pp. 411-412). Architectural Institute of Japan Conference (in Japanese).

Chang, C.-F., \& Chen, J.-W. (2006). The experimental investigation of concrete carbonation depth. Cement Concrete Research, 22(36), 1760-1767.

Durability of reinforced concrete. (1963). Kajima Technical Research Institute Version section.

Fukushima, T. (1991). Theoretical predictive methods and numerical analysis for the progress of neutralization of concrete. Proceedings of Japanese Architectural Institute, $428,1-15$. (in Japanese).

Hasegawa, T., Kashino, N., Hirata, N., Motegi, T., \& Hirose, T. (2000). A study on the investigation methods on deterioration of surface finishing paintings for reinforced concrete urban collective housings: part 2 . The results of accelerated deterioration tests and natural exposure tests. Japan Society for Finishings Technology, 10, 25-28 (in Japanese).

Hasegawa, T., \& Senbu, O. (2009-2010). Changes in temperature or humidity of the concrete surface construction materials, finishing materials surface modification in Sapporo City. Japan Society for Finishing Technology, 2(6), 139-142. (in Japanese).

Houst, Y. F., \& Wittmann, F. H. (1994). Influence of porosity and water content on the diffusivity of $\mathrm{CO}_{2}$ and $\mathrm{O}_{2}$ through hydrated cement paste. Cement and Concrete Research, 24(6), 1165-1176.

Hwang, K., Takafumi, N., \& Fuminori, T. (2001). Prediction model of carbonation process rate of concrete using fly ash. 
Journal of Structural and Construction Engineering AIJ, 22(541), 9-15 (in Japanese).

Kanematsu, M., Matsushita, T., \& Park, D.-C. (2005). Study on the carbonation suppressive effects of concrete by finishing materials for building. Proceeding Japan Concrete Institute, 27(1), 637-642. (in Japanese).

Lee, Y., \& Masuda, Y. (2010). Analytical study about the carbonation progress of concrete depending on the quality of the surface layer. Transactions of AIJ, Journal of Structural and Construction Engineering, 75(3), 649 (in Japanese).

Li, C.-H., \& Ishida, T. (2006). Carbonation model of cement hydration products based on micro-pore structure and mass transport. Proceedings of Japan Concrete Institute, 28(1), 701-706. (in Japanese).

Ngala, V. T., \& Page, C. L. (1997). Effects of carbonation on pore structure and diffusion properties of hydrated cement pastes. Cement and Concrete Research, 27(7), 995-1007.

Papadakis, V. G., Vayenas, C. G., \& Fardis, M. N. (1991). Physical and chemical characteristics affecting the durability of concrete. ACI Materials Journal, 9(2), 186-196.

Park, D.-C. (2007). Analytic research about the prediction of long-term neutralization focused on the reaction and diffusion of calcium hydroxide. Transactions of AIK, Journal of Structural and Construction Engineering, 23(8), 99-107 (in Korean).

Park, D.-C. (2008). Carbonation of concrete in relation to $\mathrm{CO}_{2}$ permeability and degradation of coatings. Construction and Building Materials, 22(11), 2260-2268.

Park, J., Hasegawa, T., Kashino, N., Senbu, O., \& Hamasaki, H. (2011). Various properties of primary and improved finishing coating materials exposed to outdoor for 10 years: Part 2: Carbonation preventive effects of finishing coating materials. Japan Society for Finishing Technology, 10, 25-28 (in Japanese).

Tanano, H., \& Masuda, Y. (1988). Carbonation of concrete progress prediction model. Concrete Research and Technology, 2(1), 125-133 (in Japanese).

Toshio, I. (1991). Study on durability design of reinforced concrete buildings based on the rate of neutralization of concrete. Osaka University Thesis for Ph.D. Degree (in Japanese).

Yoshihiro, M., \& Tanano, H. (1991). Mathematical model on process of carbonation of concrete. Concrete Research and Technology, 2(1), 248 (in Japanese). 